\title{
APPLICATION OF RESPONSE SURFACE METHODOLOGY TO ENHANCEMENT OF BIOMASS PRODUCTION BY LACTOBACILLUS RHAMNOSUS E/N
}

\author{
Magdalena Polak-Berecka ${ }^{1}$, Adam Waśko ${ }^{1}$, Monika Kordowska-Wiater ${ }^{1 *}$, Zdzisław Targoński ${ }^{1}$, Agnieszka Kubik-Komar ${ }^{2}$ \\ ${ }^{1}$ Department of Biotechnology, Human Nutrition and Science of Food Commodities, University of Life Sciences in Lublin,
} Skromna 8 20-704 Lublin, Poland; ${ }^{2}$ Department of Applied Mathematics and Computer Science, University of Life Sciences in Lublin, Poland.

Submitted: May 17, 2010; Approved: May 16, 2011.

\begin{abstract}
Response surface methodology (RSM) was employed to study the effects of various medium components on biomass production by Lactobacillus rhamnosus E/N. This strain is commonly used in the pharmaceutical and food industries due to its beneficial effect on the human gut and general health. The best medium composition derived from RSM regression was (in g/l) glucose 15.44, sodium pyruvate 3.92, meat extract 8.0, potassium phosphate 1.88, sodium acetate 4.7, and ammonium citrate 1.88 . With this medium composition biomass production was $23 \mathrm{~g} / 1$ of dry cell weight after $18 \mathrm{~h}$ of cultivation in bioreactor conditions, whereas on MRS the yield of biomass was $21 \mathrm{~g} / 1$ of dry cell weight. The cost of $1 \mathrm{~g}$ of biomass obtained on MRS broth was calculated at the level of $0.44 €$ whereas on the new optimal medium it was $25 \%$ lower. It may be concluded then, that the new medium, being cheaper than the control MRS allows large scale commercial cultivation of the L. rhamnosus strain. This study is of relevance to food industry because the possibility to obtain high yield of bacterial biomass is necessary step in manufacturing of probiotic food.
\end{abstract}

Key words: response surface methodology, Lactobacillus rhamnosus, medium selection, biomass production.

\section{INTRODUCTION}

Lactobacilli are members of the heterogeneous group of lactic acid bacteria (LAB) and many of them are used as probiotics. The main reason for the choice of these bacteria are their documented health benefits $(11,10)$. By competing for adhesion sites and nutrients and producing antimicrobial substances, lactobacilli can decrease the levels of potentially pathogenic bacteria. Establishment of pathogens in the gastrointestinal tract is connected with the mechanism of biosynthesis of inhibitory substances. Another benefit from diet supplementation with probiotics is immunomodulation (9). Probiotics play a regulatory role in allergic diseases (20). Lactic acid bacteria contribute to relief of lactose intolerance symptoms. It has also been reported that probiotic LAB reduce LDL-cholesterol and are successfully used in the treatment and prevention of colorectal cancer (14).

Strains of Lactobacillus rhamnosus due to their probiotic

\footnotetext{
*Corresponding Author. Mailing address: Department of Biotechnology, Human Nutrition and Science of Food Commodities, University of Life Sciences in Lublin, Skromna 8 20-704 Lublin, Poland; Tel.: +48 814623356 Fax +48 814623 400.; E-mail: monika.kordowska-wiater@up.lublin.pl
} 
activity, have been increasingly applied in food supplements and novel pharmaceutical products. L. rhamnosus has been for many years added to new generation fermented food such as bioyoghurts (15). This strain was also used as a probiotic culture in ice cream and cheese manufacture $(4,6,25)$, and was applied to fresh-cut apple wedges or to fruit juices for their fortification as an alternative probiotic food choice for consumers intolerant to dairy products $(23,26)$. These strains are resistant to commonly used antibiotics, which is a good reason for their use simultaneously with antibiotic therapy (24). For those reasons, the possibility of cheap and fast cultivation of lactobacilli is gaining in importance. The growth activity of this genus is strictly connected with medium formulation because lactic acid bacteria are fastidious in their nutrient requirements (1).

Response surface methodology (RSM) can be used to evaluate the relative significance of several factors in the presence of complex interactions. It is a powerful technique for testing multiple-process variables because fewer experimental trials are needed as compared with the study of one variable at a time. RSM answers the question of how to select the levels for the applied factors to obtain the desirable, smallest or largest, value of the response function in a reduced number of experiments (12). This technique includes primary screening of variables by the application of "one variable at a time" method or Plackett-Burman design $(27,21)$ as well as using a design for fitting the chosen model (19). The most popular approach is based on full factorial central composite design (CCD), which enables one to estimate the coefficients of a second-order model.

In the present work, we used RSM to examine the effect of various carbon and complex nitrogen sources as well as growth factors in media on the yield of biomass of the probiotic strain $L$. rhamnosus E/N. The aim of our study was to choose the best carbon and nitrogen sources and to compose a cheap medium for effective biomass concentration of $L$. rhamnosus $\mathrm{E} / \mathrm{N}$.

\section{MATERIALS AND METHODS}

\section{Strain and culture condition}

Lactobacillus rhamnosus strain $\mathrm{E} / \mathrm{N}$ obtained from Biomed Serum and Vaccine Production Plant Ltd. in Lublin (Poland) was used in all experiments. The bacteria were stored at $-80^{\circ} \mathrm{C}$ in MRS medium with an addition of $20 \%(\mathrm{v} / \mathrm{v})$ glycerol. The strain was revitalized in MRS broth (BTL, Poland) at $37^{\circ} \mathrm{C}$ for $24 \mathrm{~h}$ before use.

Different sources of carbon were tested for their influence on the growth of Lactobacillus. They included glucose $(\mathrm{POCH}$, Poland), glucose with sodium pyruvate (Sigma) or with sodium lactate (Sigma) or with ammonium citrate (POCH, Poland), galactose (POCH, Poland), fructose ( $\mathrm{POCH}$, Poland), lactose (POCH, Poland), sucrose (POCH, Poland), maltose $(\mathrm{POCH}$, Poland), lactulose (ICN), fructooligosaccharides (Arnaut), and maltodextrins DP 4-7 and 13-17 (Sigma). The MRS medium containing each carbon source separately at a concentration of $20 \mathrm{~g} / 1$ and $\mathrm{pH} 6.2$ was distributed into tubes and sterilized at $121^{\circ} \mathrm{C}$ for $15 \mathrm{~min}$. The media were complemented with multiple carbon sources according to Bajpaj-Dikshit et al. (3).

The effect of the optimal concentration of a complex source of nitrogen was examined in modified MRS broth, in which yeast extract, meat extract and pepton $\mathrm{K}$ were used at different concentrations (Table 1). The media prepared in tubes were pasteurized in a Koch apparatus $\left(100^{\circ} \mathrm{C}\right)$ for $20 \mathrm{~min}$.

Table 1. Concentrations of complex nitrogen sources in modified MRS broth

\begin{tabular}{cccc}
\hline Dilutions of nitrogen sources in & \multicolumn{3}{c}{ Complex nitrogen sources (g/l) } \\
\cline { 2 - 4 } relation to MRS broth & Yeast extract & Meat extract & Pepton K \\
\hline $10 \mathrm{x}$ & 0.40 & 0.80 & 1.0 \\
$25 \mathrm{x}$ & 0.16 & 0.32 & 0.4 \\
$50 \mathrm{x}$ & 0.08 & 0.16 & 0.2 \\
$75 \mathrm{x}$ & 0.05 & 0.11 & 0.13 \\
$100 \mathrm{x}$ & 0.04 & 0.08 & 0.10 \\
$500 \mathrm{x}$ & 0.01 & 0.02 & 0.02 \\
\hline
\end{tabular}


The effect of amino acids and vitamins from B group on bacterial growth was also investigated. The modified MRS medium containing 100 times lower concentrations of complex nitrogen sources was supplemented with the L form of amino acids (Pro, Ser, Val, Leu, Ile, His, Trp, Tyr, Thr, Met, Glu, and Phe) at a concentration of $0.1 \mathrm{mg} / \mathrm{ml}$ or with vitamins (biotin, folic acid, nicotinic acid, pantothenic acid, pyridoxal, riboflavin, thiamine, and cyanocobalamine) at a concentration of $0.001 \mathrm{mg} / \mathrm{ml}$. The vitamin solutions were filter-sterilized and added to the pasteurized cultivation medium in tubes prior to inoculation.

A revitalized culture of $L$. rhamnosus $\mathrm{E} / \mathrm{N}$ was used to prepare $24 \mathrm{~h}$ inocula in MRS medium, $\mathrm{pH} 6.3 \pm 0.1$. Each kind of medium in tubes was inoculated with bacteria at a concentration of $2.5 \%(\mathrm{v} / \mathrm{v})$, and the cultures were incubated at $37^{\circ} \mathrm{C}$ for $24-48 \mathrm{~h}$ in relatively anaerobic conditions. Every $2 \mathrm{~h}$, samples were collected from the stationary cultures, and an analysis of optical density (OD) was carried out. OD was measured at $600 \mathrm{~nm}$ using a Biorad spectrophotometer. Biomass concentration was determined using a standard curve of $\mathrm{OD}_{600}$ against dry cell weight.

\section{RSM experimental design}

Plackett-Burman design was used in order to limit the number of the studied variables by choosing the media which influenced the biomass value to the largest extent. The results of the analysis of this design are presented in the form of a Pareto chart.

Central composite design was chosen to estimate the response calculated according to the following form of a second degree polynomial equation (7):

$$
Y=\beta_{0}+\sum \beta_{i} X_{i}+\sum \beta_{i i} X_{i}^{2}+\sum \beta_{i j} X_{i} X_{j}
$$

where $Y$ is the predicted response variable, $\beta_{0}$ is the interception, $\beta_{i}$ are linear coefficients, $\beta_{i i}$ are quadratic coefficients, and $\beta_{i j}$ are coefficients of the interaction. $X_{i}$ and $X_{j}$ represent the chosen independent variables.
Each variable was set at a low and a high level. The low level was fixed far from the high one in order to differentiate the influence of the media on the biomass production. As a consequence, the minimum value obtained as a star point was set at zero (21).

The results of the analysis of this design were expressed in terms of polynomial coefficients, and the significance of the model was verified by applying the ANOVA analysis. Additionally $\mathrm{R}$ and $\mathrm{R}^{2}$ values were calculated to measure the goodness of fit of this regression model. The relationships between response value and the chosen media were represented in the form of $3 \mathrm{D}$ response surface plots.

Statistica version 7 (StatSoft, USA) was used to generate design matrices and plots as well as to calculate the results of the analyses.

\section{Verification of the statistical model in stationary and bioreactor conditions}

On the basis of the results obtained from statistical analysis, the optimal medium was composed. After pasteurization at $100^{\circ} \mathrm{C}$ for $20 \mathrm{~min}$, tubes were inoculated with the Lactobacillus strain at a concentration of $2.5 \%(\mathrm{v} / \mathrm{v})$. Incubation continued at $37^{\circ} \mathrm{C}$ for $24 \mathrm{~h}$. Then, samples were collected to determine biomass concentration. The experiments were done in triplicate. The culture of Lactobacillus rhamnosus $\mathrm{E} / \mathrm{N}$ was also run in the same medium in a bioreactor (Biostat, Sartorius, Germany). Four $\mathrm{pH}$ values were tested: 6.3 (as a control), 4.5, 5.0, and 5.5. The working volume was $500 \mathrm{ml}$ in a 11 vessel with stirring (100 rpm). Rods were incubated at $37^{\circ} \mathrm{C}$ for $24 \mathrm{~h}$ in relatively anaerobic conditions. Samples of the culture were examined for biomass concentration using $\mathrm{OD}_{600}$ analysis.

\section{RESULTS}

\section{Preliminary tests}

First, screening experiments were performed to evaluate the efficacy of the different kinds of carbon sources on the 
yields of biomass of L. rhamnosus E/N. Among the examined monosaccharides, glucose and galactose gave promising results at biomass production levels of 15.1 and $18.2 \mathrm{~g} / \mathrm{l}$ dry cell weight (d.c.w), respectively. Lactose was the only disaccharide suitable for high biomass production (20.0 g/l d.c.w). The best results were obtained when glucose was used simultaneously with pyruvate or lactate, or citrate, giving biomass concentrations of $25.6 \mathrm{~g} / 1,24.8 \mathrm{~g} / 1$, and $21.0 \mathrm{~g} / \mathrm{l}$, respectively (Fig. 1). Glucose + pyruvate were chosen as a carbon source for further experiments.
The optimal concentration of complex nitrogen sources, mineral and organic salts for the growth of L. rhamnosus $\mathrm{E} / \mathrm{N}$ was estimated at the level of $0.22 \mathrm{~g} / \mathrm{l}$, which corresponds to the $100 x$ dilution of nitrogen sources in relation to MRS broth. Any positive effect on bacterial growth was not observed after amino acids supplementation at the level of $0.1 \mathrm{mg} / \mathrm{ml}$. The analyzed vitamins did not sufficiently influence the growth of the examined bacteria when they were added to the medium at a concentration of $0.001 \mathrm{mg} / \mathrm{ml}$. The data obtained were used in the design of a response surface methodology.

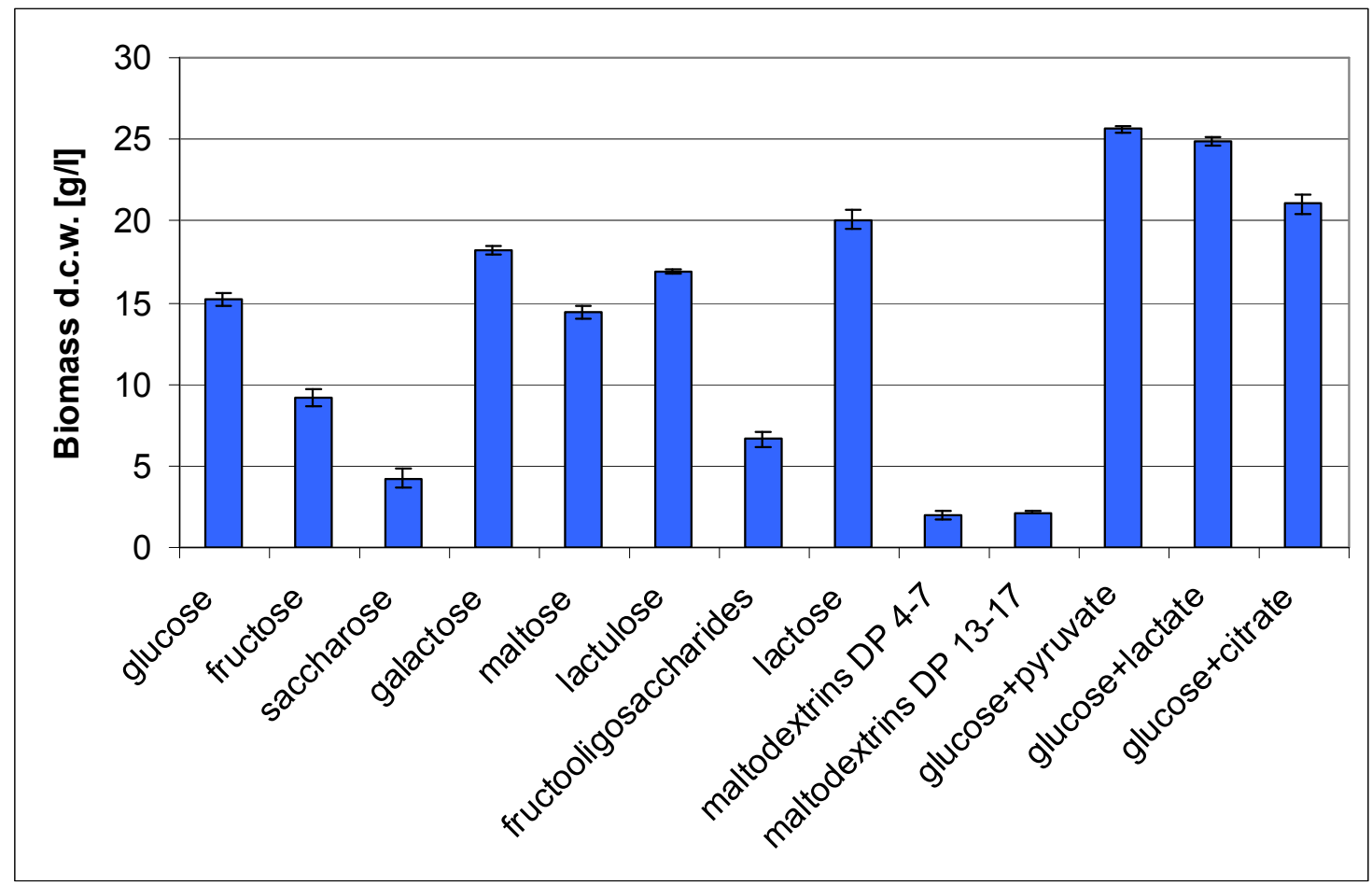

Figure 1. Effect of various carbon sources on the growth of $L$. rhamnosus $\mathrm{E} / \mathrm{N}$ after $24 \mathrm{~h}$ of incubation.

\section{Central composite design}

Variables such as glucose + pyruvate $\left(X_{1}\right)$, meat extract $\left(X_{2}\right)$ as well as organic and inorganic salts $\left(X_{3}\right)$ were chosen for further studies on the basis of the results of the analysis of Plackett-Burman design (Table 2), which are presented in the Pareto chart (Figure 2) as the absolute values of effect estimates. The increase in the values for these media influenced biomass production the most, compared to the other media.

$X_{1}, X_{2}$ and $X_{3}$ were used as independent variables in the $2^{3}$ full factorial central composite design containing low and high levels of variables, six star points with $\alpha= \pm 1.68$ and the same number of replicates at centre points (Table 3 ).

The following regression function describing the relationships between the chosen media and biomass 
production was obtained as a result of CCD analysis:

$Y=-1.24379+0.96775 X_{1}-0.03680 X_{1}^{2}+1.62525 X_{2}-0.11784 X_{2}^{2}+$ $0.39791 X_{3}-0.03009 X_{3}^{2}+0.06152 X_{1} X_{2}-0.00465 X_{1} X_{3}+0.02464 X_{2} X_{3}$ (2)

The results of ANOVA for the current model indicated its high statistical significance (Tab. 4). The goodness of fit of the model was checked by the correlation coefficient $\mathrm{R}=0.955008$ and the determination coefficient $\mathrm{R}^{2}=0.91204$, the high values of which confirmed the high agreement between the experimental and the predicted values as well as the high percentage of total variations explained by this model.

The relationship between the independent variables and the response is presented in a graphical form in Figures 3-5. The-three dimensional response surface plots illustrate the interactive effects of the media on biomass production. The optimum medium composition for the growth of L. rhamnosus $\mathrm{E} / \mathrm{N}$ is as follows: glucose $15.44 \mathrm{~g} / \mathrm{l}$, sodium pyruvate $(3.92$ $\mathrm{g} / \mathrm{l})$, meat extract $(8.0 \mathrm{~g} / \mathrm{l})$, potassium phosphate $(1.88 \mathrm{~g} / \mathrm{l})$, sodium acetate $(4.7 \mathrm{~g} / \mathrm{l})$, and ammonium citrate $(1.88 \mathrm{~g} / \mathrm{l})$.

Table 2. Plackett-Burman design for seven variables

\begin{tabular}{|c|c|c|c|c|c|c|c|c|}
\hline Run & Glucose + pyruvate & Pepton K & Meat extract & Yeast extract & $\begin{array}{c}\text { Organic and } \\
\text { inorganic salts }\end{array}$ & Microelements & $\mathrm{NaCl}$ & Biomass (g/l) \\
\hline 1 & $-1^{\text {a) }}$ & -1 & -1 & 1 & 1 & 1 & -1 & 4.2139 \\
\hline 2 & 1 & -1 & -1 & -1 & -1 & 1 & 1 & 6.1327 \\
\hline 3 & -1 & 1 & -1 & -1 & 1 & -1 & 1 & 1.1805 \\
\hline 4 & 1 & 1 & -1 & 1 & -1 & -1 & -1 & 12.099 \\
\hline 5 & -1 & -1 & 1 & 1 & -1 & -1 & 1 & 2.5366 \\
\hline 6 & 1 & -1 & 1 & -1 & 1 & -1 & -1 & 22.085 \\
\hline 7 & -1 & 1 & 1 & -1 & -1 & 1 & -1 & 3.1762 \\
\hline 8 & 1 & 1 & 1 & 1 & 1 & 1 & 1 & 25.413 \\
\hline
\end{tabular}

\begin{tabular}{lcc}
\hline Independent variables & \multicolumn{2}{c}{ a) Code levels $\mathbf{( g / l )}$} \\
\cline { 2 - 3 } & $\mathbf{- 1}$ & $+\mathbf{1}$ \\
\hline Glucose + pyruvate & 0.8 & 20 \\
Pepton K & 0.2 & 10 \\
Meat extract & 0.16 & 8 \\
Yeast extract & 0.08 & 4 \\
Organic and inorganic salts & 0.9 & 9 \\
Microelements & 0.02 & 0.24 \\
NaCl & 0 & 30 \\
\hline
\end{tabular}

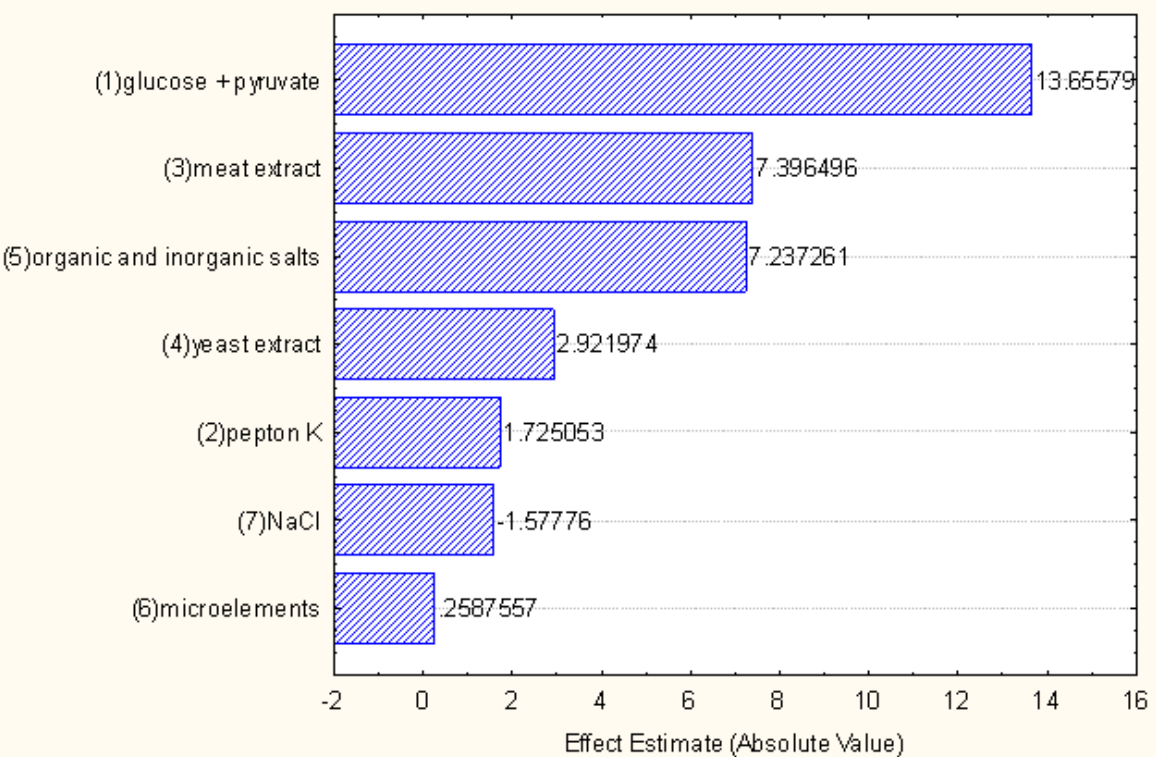

Figure 2. Pareto chart - a ranking of variables investigated in the PlackettBurman design. 
Table 3. Central composite design matrix with values of biomass

\begin{tabular}{cccc}
\hline Glucose + pyruvate $\left(\boldsymbol{X}_{\mathbf{1}}\right)(\mathbf{g} / \mathbf{l})$ & Meat extract $\left(\boldsymbol{X}_{\mathbf{2}}\right)(\mathbf{g} / \mathbf{l})$ & Organic and inorganic salts $\left(\boldsymbol{X}_{\mathbf{3}}\right)(\mathbf{g} / \mathbf{l})$ & Biomass $(\mathbf{g} / \mathbf{l})$ \\
\hline 0.8 & 0.16 & 0.9 & 1.7988 \\
0.8 & 0.16 & 9 & 2.1465 \\
0.8 & 8 & 0.9 & 5.6417 \\
0.8 & 8 & 9 & 6.9501 \\
20 & 0.16 & 0.9 & 4.2113 \\
20 & 0.16 & 9 & 3.2319 \\
20 & 8 & 0.9 & 16.711 \\
20 & 8 & 9 & 17.900 \\
0 & 4.08 & 4.95 & 2.5101 \\
26.528 & 4.08 & 4.95 & 13.749 \\
10.4 & 0 & 4.95 & 2.2288 \\
10.4 & 10.665 & 4.95 & 20.9442 \\
10.4 & 4.08 & 0 & 12.0005 \\
10.4 & 4.08 & 11.754 & 14.9889 \\
10.4 & 4.08 & 4.95 & 14.4713 \\
10.4 & 4.08 & 4.95 & 14.3758 \\
10.4 & 4.08 & 4.95 & 13.8185 \\
10.4 & 4.08 & 4.95 & 14.5509 \\
10.4 & 4.08 & 4.95 & 13.8822 \\
10.4 & 4.08 & 4.95 & 14.0892 \\
\hline
\end{tabular}

Table 4. Analysis of variance for the current regression model

\begin{tabular}{cccccc}
\hline Source of variation & Sum of square & Degree of freedom & Mean Square & F-Value & p-Value \\
\hline Model & 660.5372 & 9 & 73.39302 & 11.52083 & 0.000345 \\
Error & 63.70465 & 10 & 6.370465 & & \\
\hline
\end{tabular}

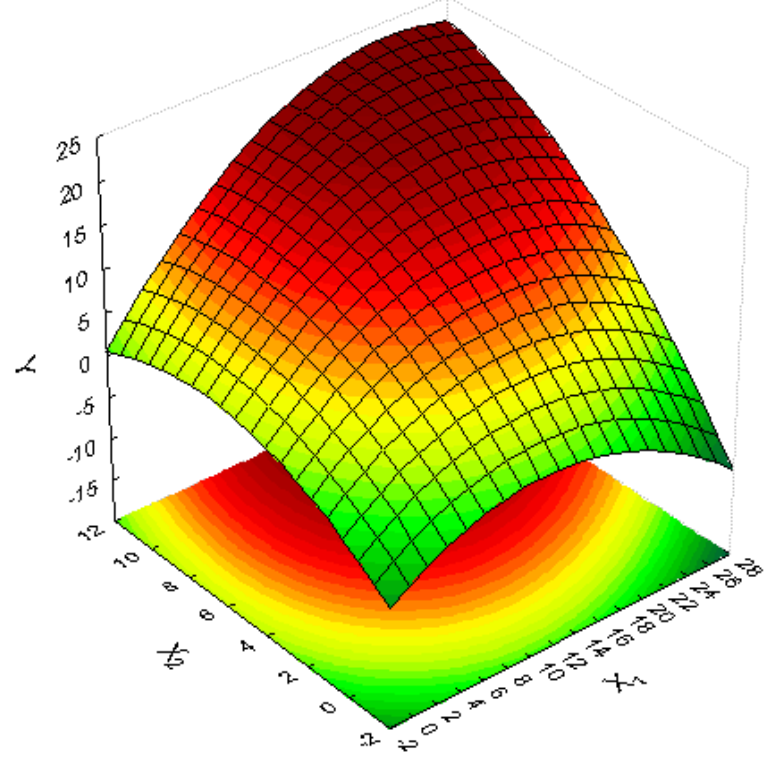

Figure 3. Influence of the interaction between glucose + pyruvate $\left(X_{1}\right)$ and meat extract $\left(X_{2}\right)$ on the biomass production $(Y)$, with organic and inorganic salts $\left(X_{3}\right)$ at their center point level. 


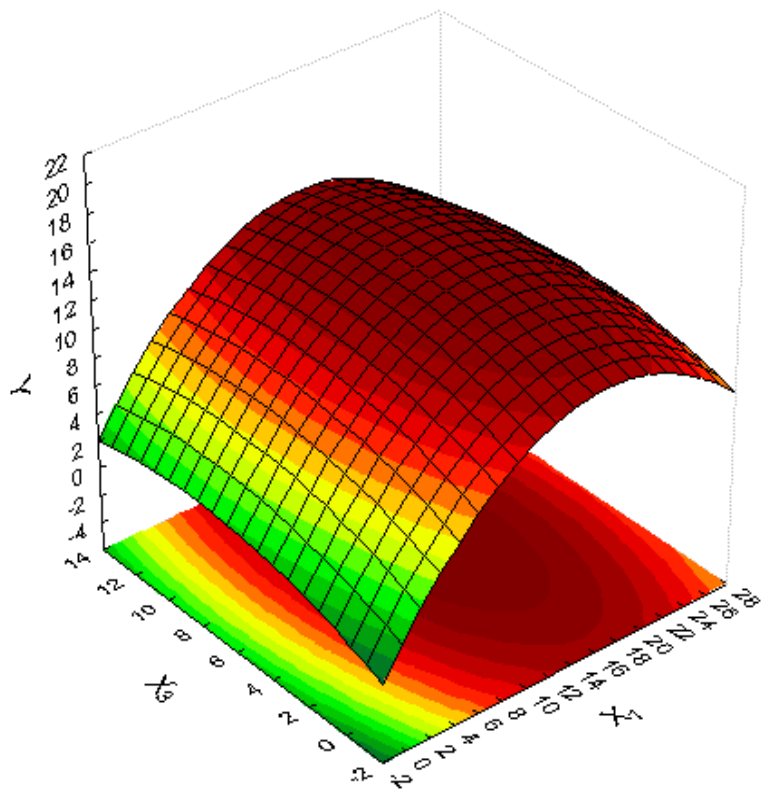

Figure 4. Influence of the interaction between glucose + pyruvate $\left(X_{1}\right)$ and organic and inorganic salts $\left(X_{3}\right)$ on the biomass production $(Y)$, with meat extract $\left(X_{2}\right)$ at its center point level.

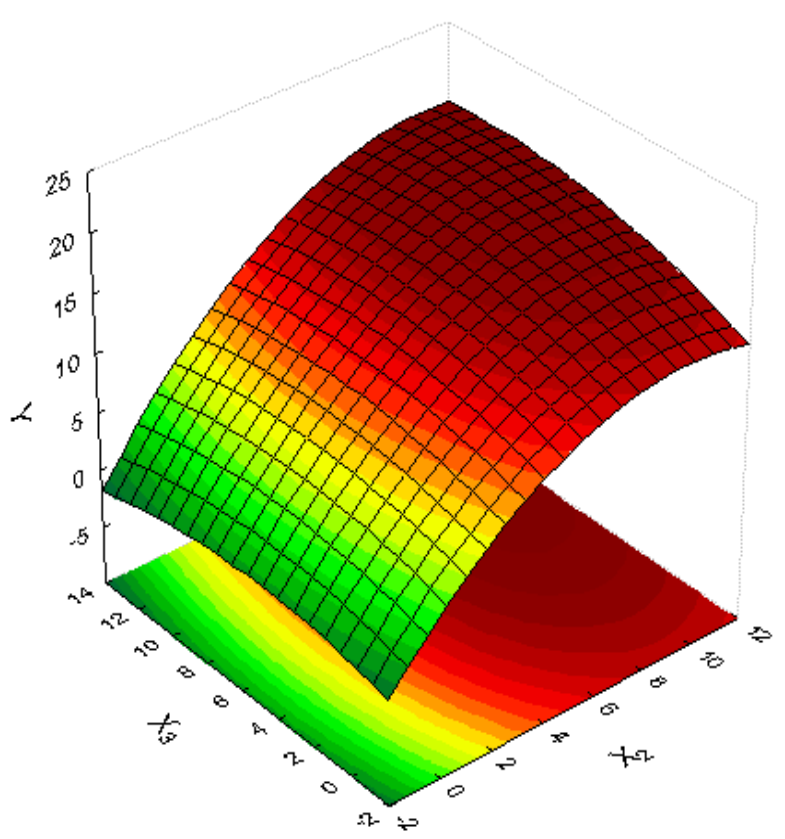

Figure 5. Influence of the meat extract $\left(X_{2}\right)$ and organic and inorganic salts $\left(X_{3}\right)$ on biomass production $(Y)$, with glucose + pyruvate $\left(X_{1}\right)$ at its center point level.

\section{Verification of the model in a bioreactor}

The yield of biomass obtained under bioreactor conditions was in agreement with the results from the stationary culture. Our results show that the maintenance of $\mathrm{pH}$ at a constant level is important for biomass production by L. rhamnosus $\mathrm{E} / \mathrm{N}$. When $\mathrm{pH}$ value was maintained at the level of 5.0, the highest yield of Lactobacillus biomass was obtained on the optimal medium. After $24 \mathrm{~h}$ of cultivation dry cell weight was $24 \mathrm{~g} / \mathrm{l}$ (Fig. 6). 


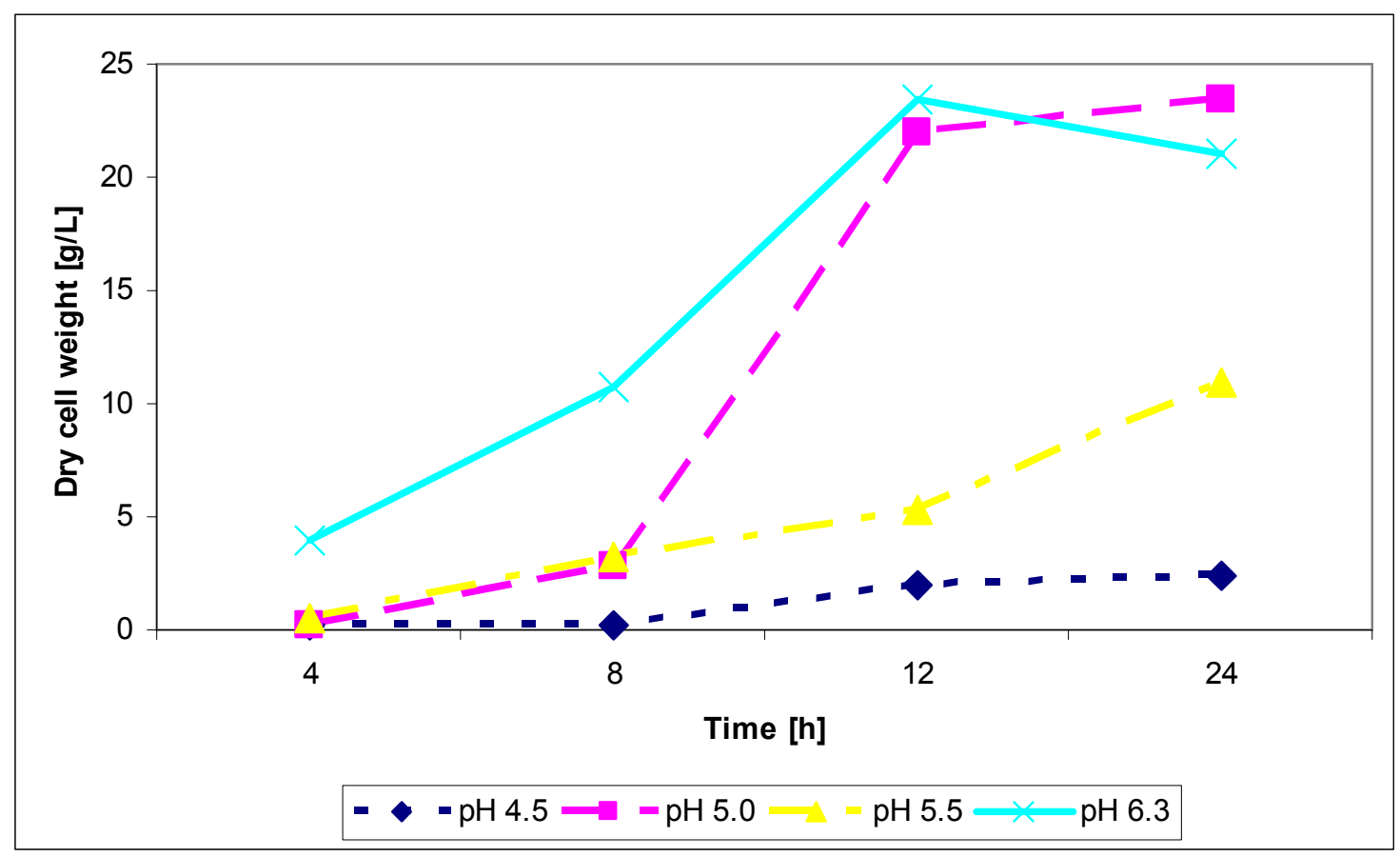

Figure 6. Growth of L. rhamnosus $\mathrm{E} / \mathrm{N}$ in the optimal medium ( $\mathrm{pH} 4.5, \mathrm{pH} 5.0, \mathrm{pH} 5.5)$ in comparison with the MRS medium ( $\mathrm{pH}$ 6.3) in bioreactor conditions.

\section{DISCUSSION}

The yields of biomass of L. rhamnosus E/N after 24-h culture in MRS containing different carbon sources are shown in Figure 1. The results demonstrate that mixtures of glucose with salts of organic acids were optimal complex carbon sources for the growth of the examined strain. However, the best growth was observed when sodium pyruvate was added. In this case bacteria achieved stationary phase after six hours of incubation whereas in media containing other carbon sources this state was achieved after $16-18 \mathrm{~h}$. Our observation is in agreement with the findings of other researchers. As regards the effect of carbohydrates, Mataragas et al. (18) reported that glucose concentration did not improve the total biomass produced by Leuconostoc mesenteroides and Lactobacillus curvatus, whereas Liew et al. (16) showed a slight effect of glucose on the cell number of Lactobacillus rhamnosus. Bajpaj-Dikshit et al. (3) reported that L. rhamnosus increased the maximum growth rate nearly 1.4 -fold when it cometabolized sodium pyruvate with glucose. It appears that among the various carbon sources studied, the yield of biomass was mostly influenced by the increase in the concentration of glucose + sodium pyruvate which is the preferred substrate for the growth of L. rhamnosus.

Meat extract had a great positive effect on the growth of the examined bacteria, whereas the effect of yeast extract, and pepton $\mathrm{K}$ was slight and similar. We took into consideration the fact that meat extract contains a larger amount of total nitrogen $(12 \% \mathrm{w} / \mathrm{v})$ than YE $(10 \% \mathrm{w} / \mathrm{v})(8)$ and the fact that some authors recommended adding ammonium salts $(13,29)$ and citrate (2) into the medium as they increased the yield of biomass production, so meat extract and organic and inorganic salts (potassium phosphate, sodium acetate, and ammonium citrate) were selected for further analysis.

An increase in $\mathrm{NaCl}$ and, to a lesser extend, microelements had a negative effect on biomass production. 
The shapes of the response surface plots presented in Figures 3-5 provide some information about the interactions among the studied media (7). The nearly circular nature of the shape in Figure 3 points to no interaction between glucose + pyruvate and meat extract, while the rest of the shapes (Figures 4-5) presenting ellipses indicate a strong interaction among organic and inorganic salts and the other studied medium components. It can also be noticed that the changes in glucose + pyruvate and meat extract concentrations affected biomass production much more than changes in the concentrations of organic and inorganic salts.

The search for the optimum (maximum) value of the response was limited to the low-high interval of the studied media. For such assumptions the following values were calculated: $X_{1}=19.36, X_{2}=8, X_{3}=8.46$ with the corresponding $Y=20.805$.

Our experiments indicate that increasing the scale of the biomass production of $L$. rhamnosus $\mathrm{E} / \mathrm{N}$ requires maintaining a constant $\mathrm{pH}$ of the medium at the level 5.0. This result could be explained by differences in lactate concentration in the culture medium and in $\mathrm{pH}$ gradient value. The elevated content of the ionic lactate form at high $\mathrm{pH}$ values damaged membrane integrity which led to decrease in viability. In contrast, the high $\mathrm{pH}$ gradient observed throughout $\mathrm{pH} 5$ cultures was associated with an enhanced energetic level, which helped the cells maintain their physiological state (22). Our results are consistent with those reported by Rault et al. (22). Such results may be of benefit to industrial starter producers and fermentedproduct manufacturers by allowing them to better control the quality of their starters.

With the optimal medium composition biomass concentration was $23 \mathrm{~g} / \mathrm{l}$ of dry cell weight after $18 \mathrm{~h}$ of incubation in bioreactor culture. The yield presented here is not very impressive compared with the control MRS medium (22.5 $\mathrm{g} / \mathrm{l}$ ), but in the control, after $18 \mathrm{~h}$ of incubation, bacterial growth decreased whereas in the optimal medium the growth curve was sloping upward. Many reports on the production of
L. rhamnosus biomass $(5,17,28)$ describe yields which are generally lower than $15 \mathrm{~g} / \mathrm{l}$. The biomass yield in our experiment was significantly higher because of the application of a mixed carbon source (glucose + pyruvate) and a constant $\mathrm{pH}$ level of 5.0.

The analysis of costs indicates that the price of 11 of the optimal medium is $7.54 €$ and the price of $1 \mathrm{~g}$ of biomass produced using this medium is at the level of $0.33 €$. Considering the cost of the control MRS medium (9.92 $€$ ), it may be concluded that the new medium can not only be successfully used for effective biomass production by $L$. rhamnosus E/N, but can also significantly lower the costs of this production. The final yield and costs were compared with results of other authors $(5,28)$. They reported a growth yield of $4.0 \mathrm{~g} / \mathrm{l}$ dry cell weight for L. rhamnosus grown for 26 hours on a defined medium costing $33.34 € / 1$ (28) or $10.50 \mathrm{~g} / \mathrm{l}$ costing $56.76 € / 1(5)$.

In view of the above, the lower costs of the new, optimal medium developed in this study and the high biomass concentration of the examined Lactobacillus strain grown on this medium could be of potential practical value to industry.

\section{ACKNOWLEDGEMENTS}

This work was financially supported by grant R12 06303 from The Polish Ministry of Science and Higher Education.

\section{REFERENCES}

1. Aasen, M.; Moretro, T.; Katla, T.; Axelsson, L.; Storro, I. (2000). Influence of complex nutrients, temperature and $\mathrm{pH}$ on bacteriocin production by Lactobacillus sakei CCUG 42687. Appl. Microbiol. Biotechnol. 53, 159-166.

2. Amrane, A.; Prigent, Y. (1998). Influence of yeast extract concentration on batch cultures of Lactobacillus helveticus: growth and production coupling. World J. Microbiol. Biotechnol. 14, 529-534.

3. Bajpaj-Dikshit, J.; Suresh, A.K.; Venkatesh, K.V. (2003). An optimal model for representing the kinetics of growth and product formation by Lactobacillus rhamnosus on multiple substrates. J. Biosci. Bioengin. 96, 481-486. 
4. Basyigit, G.; Kuleasan, H.; Karahan, A.G. (2006). Viability of humanderived probiotic lactobacilli in ice cream produced with sucrose and aspartame. J. Ind. Microbiol. Biotechnol. 33 (9), 796-800.

5. Berry, R.; Franco, C.M.; Zhang, W.; Middelberg, A.P. (1999). Growth and lactic acid production in batch culture of Lactobacillus rhamnosus in a defined medium. Biotechnol. Lett. 21, 163-167.

6. de Vrese, M.; Schrezenmeir, J. (2008). Probiotics, Prebiotics, and Synbiotics. Adv. Biochem. Engin. Biotechnol. 111, 1-66.

7. Elibol, M. (2004). Optimization of medium composition for actinorhodin production by Streptomyces coelicolor A3(2) with response surface methodology. Process Biochem. 39, 1057-1062.

8. Fung, W.Y.; Woo, Y.P.; Liong, M.T. (2008). Optimization of growth of Lactobacillus acidophilus FTCC 0291 and evaluation of growth characteristics in soy whey medium: a response surface methodology approach. J. Agric. Food Chem. 56, 7910-7918.

9. Grönlund, M.M.; Arvilommi, H.; Kero, P.; Lehtonen, O.P.; Isolauri, E. (2000). Importance of intestinal colonization in the maturation of humoral immunity in early infancy: a prospective follow up study of healthy infants aged 0-6 months. Arch. Dis. Childhood, 83, 186-192.

10. Guandalini, S.; Pensabene, L.; Zikri, M.A.; Dias, J.A.; Casali, L.G.; Hoekstra, H.; Kolacek, S.; Massar, K.; Micetic-Turk, D.; Papadopoulou, A.; de Sousa, J.S.; Sandhu, B.; Szajewska, H.; Weizman, Z. (2000). Lactobacillus GG administered in oral rehydration solution to children with acute diarrhea: a multicenter European trial. J. Ped. Gastroenterol. Nutr. 30, 54-60.

11. Gupta, V.; Garg, R. (2009). Probiotics. Indian J. Med. Microbiol. 27, 202-209.

12. Hanrahan, G.; Lu, K. (2006). Application of factorial designs and Response Surface Methodology in modern experimental design and optimization. Crit. Rev. Anal. Chem. 36, 141-151.

13. Heriban, V.; Sturdik, E.; Zalibera, L.; Matus, P. (1993). Process and metabolic characteristics of Bacillus coagulans as lactic acid producer. Lett. Appl. Microbiol. 16, 243-246.

14. Hirayama, K.; Rafter, J. (2000). The role of probiotic bacteria in cancer prevention. Microbs Infect. 2, 681-686

15. Libudzisz, Z. (2004). New milk fermented drinks. In: Libudzisz, Z., Walczak, P., Bardowski, J. (eds.). Lactic acid bacteria. Classification, methabolism, genetics, application. Lodz Technical University Press, Lodz, Poland, p. 75-89.

16. Liew, S.L.; Ariff, A.B.; Raha, A.R.; Ho, Y.W. (2005). Optimization of medium composition for the production of a probiotic microorganism, Lactobacillus rhamnosus, using response surface methodology. Int. J. Food Microbiol. 102, 137-142.
17. Ling, L.S.; Mohamad, R.; Rahim, R.A.; Wan, H.Y.; Ariff, A.B. (2006). Improved production of live cells of Lactobacillus rhamnosus by continuous cultivation using glucose - yeast extract medium. $J$. Microbiol. 44, 439-446.

18. Mataragas, M.; Drosinos, E.H.; Tsakalidou, E.; Metaxopoulos, J. (2004). Influence of nutrients on growth and bacteriocin production by Leuconostoc mesenteroides L124 and Lactobacillus curvatus L442. Antonie van Leeuwenhoek, 85, 191-198.

19. Myers, R.H.; Montgomery, D.C. (1995). Response Surface Methodology. Process and Product Optimization Using Designed Experiments. John Wiley \& Sons Inc., New York, USA pp. 297-340.

20. Pessi, T.; Sütas, Y.; Hurme, M.; Isolauri, E. (2000). Interleukin-10 generation in atopic children following oral Lactobacillus rhamnosus GG. Clin. Exp. Allergy, 30, 1804-1808.

21. Preetha, R.; Jayaprakash, S.N.; Rosamma, P.; Bright Singh, I.S. (2007). Optimization of carbon and nitrogen sources and growth factors for the production of an aquaculture probiotic (Pseudomonas MCCB 103) using response surface methodology. J Appl. Microbiol. 102, 1043-1051.

22. Rault, A.; Bouix, M.; Béal, C. (2009). Fermentation pH influences the physiological-state dynamics of Lactobacillus bulgaricus CFL1 during pH-controlled culture. Appl. Environment. Microbiol. 75, 4374-4381.

23. Rößle, C.; Auty, M.A.E.; Brunton, N.; Gormley, R.T.; Butler, F. (2010). Evaluation of fresh-cut apple slices enriched with probiotic bacteria. Innov. Food Scie. Emerg. Technol. 11 (1), 203-209

24. Ruszczyński, M.; Szajewska, H. (2008). Probiotics for the treatment of antibiotic-associated diarrhea. Updated meta-analysis of randomized controlled trials. Pediatria Wspolczesna, 10, 96-104.

25. Salem, M.M.E.; Fathi, F.A.; Awad, R.A. (2006). Production of functional ice cream. Deutsch. Leb. Rundschau 102 (7), 326-329.

26. Sheehan, V.M.; Ross, P.; Fitzgerald, G.F. (2007). Assesing the acid tolerance and the technological robustness of probiotic cultures for fortification in fruit juices. Innov. Food Sci. Emerg. Technol. 8, 279-284.

27. Xin, C.; Yin, L.; Guocheng, D.; Jian, C. (2005). Application of response surface methodology in medium optimization for spore production of Coniothyrium minitans in solid-state fermentation. World J. Microbiol. Biotechnol. 21, 593-599.

28. Youssef, B.; Goma, G.; Olmos-Dichara, A. (2005). Kinetic modeling of Lactobacillus casei ssp. rhamnosus growth and lactic acid production in batch cultures under various medium conditions. Biotechnol. Lett. 27, 1785-1789.

29. Zayed, G.; Winter, J. (1995). Batch and continuous production of lactic acid from salt whey using free and immobilized cultures of lactobacilli. Appl. Microbiol. Biotechnol. 44, 362-366. 